\title{
Increasing Achievement Motivation of Elementary School Students with Mild Disabilities
}

Presents specific strategies for enhancing achievement motivation that can serve as guides for instructional practices evaluation and the design of new activities

\section{By Cynthia M. Okolo, Christine M. Bahr, and J. Emmett Gardner} and J. Emmett Gardner

4 lthough we often think of learning and motivation as two separate issues, educators are paying increasing attention to the inextricable link between them. Students' achievement motivation, or their motivation to learn, affects not only how well they learn new skills and information, but also how well they use existing skills and knowledge in both familiar and novel situations (Lepper, 1983). There is convincing evidence that a variety of achievement deficits are the result of motivational problems rather than factors directly attributable to specific cognitive disabilities (e.g., Licht \& Kistner, 1986; Resnick \& Klopfer, 1989; Zigler \& Hodapp, 1986). Thus, approaches to the design of effective instructional practices and classroom management should be guided by knowledge of factors that impede or contribute to achievement motivation.

What behaviors are associated with achievement motivation? Most educators agree that students who are motivated to learn are those who pay attention to the teacher and maintain interest in academic activities, volunteer answers in class, ask for guidance when needed, persist in trying to solve problems themselves, complete activities above and beyond those required for a grade, and take risks in order to improve their own skills or knowledge. However, many students with mild disabilities appear to be uninterested or unmotivated to learn. Some students are characterized by learned helplessness and fail to put forth reasonable effort when necessary (Dweck, 1975). Others seem motivated but are overly concerned about their performance, thus avoiding the challenges inherent in difficult tasks or new academic experiences.

Motivational deficits have obvious and significant implications for students' academic progress. In particular, the motivation to pursue educational experiences, despite difficulties and setbacks, may be an essential determinant of eventual success in school and adult life. Thus, the development of students' achievement motivation is a critical goal that warrants concerted attention in special education programming.

A large and growing body of literature is available on the determinants of motivation. After an extensive review of the research, we have concluded that, in classroom situations, achievement motivation is a product of the interaction between student characteristics and instructional practices. Student characteristics that affect achievement motivation include (a) students' ability to perform a task, which includes their skills, background knowledge, and prior experiences; (b) the degree to which students value an activity and perceive it as relevant, interesting, and important; and (c) students' beliefs about learning and about themselves as learners.

As many educators have observed, students' achievement motivation can vary across situations. For example, a student who dreads a test in mathe- 
matics class may look forward to a test in driver's education class. Or, a student who never volunteers answers during class discussions may be one of the most outspoken students in a cooperative learning group. Indeed, research has shown us that achievement motivation is not a static trait, but is partially determined by characteristics of the learning environment (e.g., Brophy, 1987). This is good news for teachers, because it means that they can increase achievement motivation by considering students' motivational characteristics and adjusting the instructional environment accordingly.

The purpose of this article is to present specific recommendations for enhancing the achievement motivation of students with mild disabilities. We focus on problems and suggestions pertinent to students in first through sixth grade. Recommendations, gleaned from currently available literature, are based on empirically validated approaches to motivational enhancement. We have grouped them into five topics: (a) learner control, (b) rewards, (c) student interest, (d) classroom structure, and (e) self-efficacy and attributions. Figure 1 is a checklist that summarizes the recommendations we discuss next. We then describe a process for implementing these recommendations in the classroom. Although teachers will be unable to implement all the recommendations at one time, we hope that this synthesis of information will serve as a guide for evaluating current instructional practices and designing new activities for students.

\section{Enhancing Achievement Motivation}

\section{Learner Conirol}

Motivational theorists place the construct of personal control at the heart of human motivation (Csikszentmihalyi \& Nakamura, 1989; deCharms, 1968; Deci \& Ryan, 1985; Skinner, Wellborn, \& Connell, 1990). A number of studies have shown that offering learners options for controlling aspects of what, when, and how they learn can have a positive effect on both achievement and motivation (Deci, Schwartz, Sheinman, \& Ryan, 1981; Malone \& Lepper, 1987; Pintrich, Marx, \& Boyle, 1993). The following recommendations can assist you in deciding when and how much control to provide to learners.

1. Give students a moderate amount of choice in the classroom. Giving learners complete freedom over what and how they will learn is probably not in their best interests. This is especially true for learners with mild disabilities, who may not have the skills and metacognitive sophistication needed to make good instructional choices. However, letting students control some features of their instructional experiences, without bypassing essential information or practice opportunities, can promote both increased learning and motivation (Kinzie \& Sullivan, 1989). Areas in which you can give students control, without sacrificing important instructional information or pedagogy, include choices about when to complete tasks and how competence should be demonstrated (Stipek, 1993). For example, you might let students choose a book report, quiz, or oral presentation at the conclusion of a social studies unit. Students also can participate in decisions about how various assignments will be weighted toward their final grade. In addition, opportunities to correct one's own work can increase students' perception of control (Stipek, 1993).

2. Enhance students' perceptions of control. Keep in mind that students' perception of control is more important than the actual control they exercise in a learning situation (Stipek \& Weisz, 1981). Good teachers use this to their advantage. In cases where a high degree of student control would be impractical or undesirable, teachers can let students exercise choices among a restricted number of equally effective alternatives. For example, you might decide that appropriate rewards for a perfect record of homework completion are a weekend without homework, a free-time period, or a Friday afternoon movie. By letting students decide which of these alternatives they prefer, you can enhance their perception of control over their own learning.

3. Make sure students are aware of the degree of control they can exercise in an instructional activity. Even when provided with learning options, students may not realize they can exercise choices. In addition, students may fail to discern the relationship between the choices they make and the outcomes of an activity. To help students gain the experience necessary for mak- ing good choices in the future, you may need to make these relationships explicit by drawing attention to them or discussing them with the student (Klein \& Keller, 1990). For example, you might ask students to predict what they think will happen when they make a choice, such as studying for a test with a friend versus studying alone, and then follow up with a discussion of the outcome.

4. Take into account individual learners' characteristics when considering the instructional choices you permit them to make. Individual differences among students will mediate the impact of learner control on student achievement and motivation. Students' prior knowledge of the content to be studied is one example. Students with low prior knowledge benefit more from external structure and guidance than students with high prior knowledge /Carrier, 1984; Gay, 1986). Students' prior achievement history also will affect their perceptions of control. If a student doesn't have the skills or behaviors necessary to succeed at a task, he or she is unlikely to feel in control (Malone \& Lepper, 1987). Researchers have found that young learners make poor instructional choices (Carrier, 1984; Okolo, Hinsey, \& Yousefian, 1990), perhaps by virtue of their relative lack of experience with educational endeavors. Furthermore, some researchers have found that opportunity to exercise control has more impact on the achievement of young adolescents than on preadolescent or college-age students (Findley \& Cooper, 1983; Stipek \& Weisz, 1981).

Regardless of students' ability or inclination to make good instructional choices at the present time, they should receive the experiences and instruction they need to become good instructional decision makers. In order to become self-sufficient and selfregulated learners, students will need assistance in learning how to make good decisions. When teachers coach students to make choices that enhance their learning, both achievement and motivation improve (Hannafin, 1984).

\section{Rewards}

The use of rewards and other external incentives has a long history in the field of education. In fact, many of us would find teaching students with 

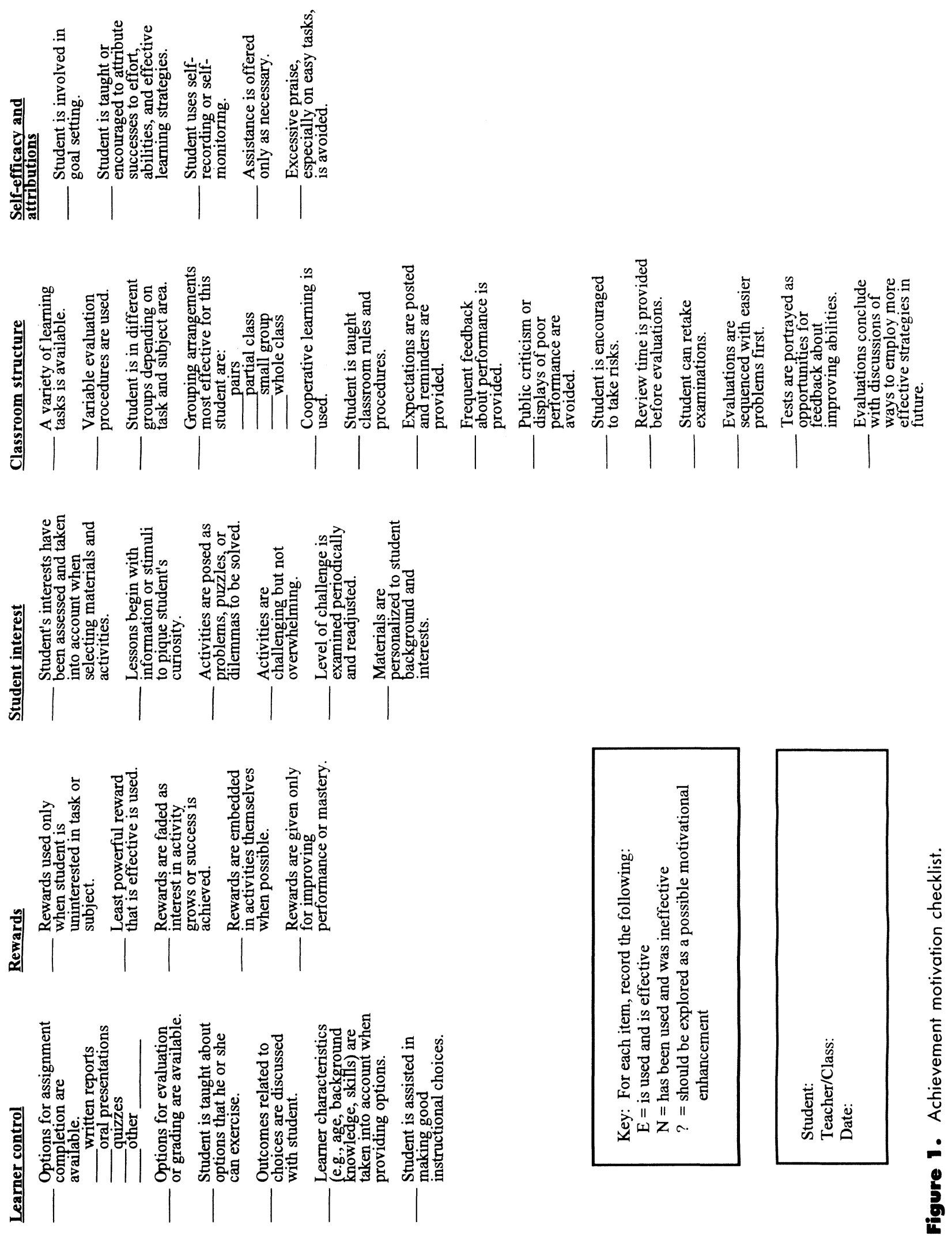
learning and behavioral problems an impossible task without occasional use of external incentives. However, research documenting the positive effects of rewards (e.g., Kazdin \& Bootzin, 1972; O'Leary \& Drabman, 1971; Rigby, Deci, Patrick, \& Ryan, 1992; Schloss \& Smith, 1994) is complemented by a body of research showing that external rewards can have a negative impact on student motivation (e.g., Deci, 1971; Greene \& Lepper, 1974; Kruglanski, Friedman, \& Zeevi, 1971; Morgan, 1984). Given that rewards can have a positive or negative impact on student motivation, depending on differences in the conditions under which they are issued, we advise teachers to use rewards in a judicious manner by considering the following recommendations.

1. Use external rewards only as necessary. Many of our special education practices are rooted in behavioral theories that stress the importance of positive reinforcement. However, even the strictest behaviorist would agree that teachers should forego external rewards and contingencies when an activity is inherently interesting to students. In these cases, rewards may diminish students' intrinsic motivation for performing a task (Lepper \& Greene, 1975). If students have little intrinsic interest in an activity, then it is acceptable to use rewards as required to encourage them to engage in the task. For example, a student who is overwhelmed by the assignment of writing a book report may be persuaded to complete the first page for the promise of 10 minutes of free time. Or, students who dislike mathematics may willingly practice their facts for 15 minutes if they are then allowed to play a computer math game. Always choose the least powerful reward necessary to get the job done (Malouf, 1983), and gradually fade incentives as students experience success or show interest in performing the activity (Lepper, 1988).

2. Minimize the salience of external rewards and incentives. Rewards can have a damaging effect on students motivation when they are overemphasized, given in an arbitrary manner, or are the most plausible explanation for engaging in an activity. When possible, embed rewards within the activity itself (Lepper \& Malone, 1987). For example, students can exercise math skills to double a cookie recipe and then enjoy the cookies they bake as a reward. Make sure that rewards are given for improved performance and mastery, thus conveying information about a student's competence, rather than as means for controlling behavior or appeasing parents and students.

\section{Student Interest}

Nearly a century ago, John Dewey (1913) suggested that interest was a primary motivator in educational settings. Many theories of learning include curiosity, challenge, and personalization as elements of instruction associated with interest. The recommendations offered next incorporate elements that are geared toward cultivating and maintaining student interest.

1. Select instructional materials and activities according to student interests. As Dewey (1913) pointed out, children divide their attention between the school work assigned to them and dreams about what they'd like to be doing instead. Perhaps the most promising strategy for promoting interest in learning is to find out what naturally interests students and to select instructional materials accordingly (Brophy, 1987; Dewey, 1913; Wlodkowski, 1986). Interest inventories, questionnaires, individual interviews with students and parents, and systematic observation of students in a variety of different settings can assist you in obtaining this information.

2. Pique students' curiosity. We become curious about something when there is an unexpected or inconsistent event in our perceptual environment, or when there is a gap between our present and desired state of knowledge (Keller, 1983). Thus, a student's curiosity and desire to learn can be aroused by introducing a change in the sensory environment or by presenting cognitive stimuli that are novel, incongruous, or incomplete. Consider different ways to pique students' curiosity at the beginning of a lesson. You might use brightly colored materials, videotapes, and films to augment printed text, or hands-on learning activities. Or, introduce instruction by describing a dilemma, posing a riddle, or pointing out a discrepancy between two sets of information. Structure activities as problem-solving situations in which students can seek out missing information, perform experiments to test hypotheses, and complete tasks to solve puzzles (Dembo, 1988). Keep in mind that activities that arouse moderate levels of curiosity may be most effective. Events that are too surprising or random may be frightening or detract from the relevant features of a learning task. Information that is too discrepant with students' initial conceptions may be impossible to assimilate.

3. Provide students with an optimal level of challenge. Researchers have speculated that an activity is optimally challenging if students have a $50 \%$ probability of succeeding at it Atkinson, 1966). However, this conceptualization doesn't take into account the fact that failure in a classroom setting is a public event with a number of negative consequences (Brophy, 1983). In particular, students with learning problems may need to feel they have much more than a $50 \%$ chance of success before they are comfortable undertaking an activity. In general, tasks should be hard enough to require a moderate amount of thought but easy enough to be completed with reasonable effort relative to an individual's skill level (Stipek, 1993). You will need to adjust the level of challenge to the needs of individuals in your classroom and reevaluate assignments on a systematic basis to maintain optimal levels of challenge. Instructional practices such as curriculum-based measurement (e.g., Fuchs \& Deno, 1991; Shinn, 1989|, in which teachers monitor student progress on a continuous basis, provide essential data for adjusting and readjusting the level of challenge confronted by each student.

4. Personalize the learning experience. Choose activities that involve domains, characters, or problems of interest to the students with whom you work (Brophy, 1987). For example, students who balk at computing the amount of time it takes a train to reach the station may be enthusiastic about figuring out the time a stock car takes to reach the finish line. Present activities in contexts that are most relevant to students' use of skills in real life and discuss how the knowledge or skills students are learning can help them in their everyday activities. For example, researchers have found that using students' names or incorporating topics in which they are interested into math problems has a positive impact on motivation and achievement (Anand $\&$ Ross, 1987; López \& Sullivan, 1992). A modification such as this can be easily 
made with a word processing program that allows you to merge a file of student names and preferred topics with a file of math problems or reading paragraphs (Beaver, 1991).

\section{Classroom Structure}

Classrooms can be organized in ways that facilitate or impede student motivation. The manner in which you organize your classroom communicates your expectations, the value you place on certain activities and behaviors, and the standards by which students are evaluated. In order to promote motivation, you may wish to consider the following factors.

1. Create a multidimensional classroom. Traditional classrooms are unidimensional: There is a common set of expectations for all students and a limited number of ways in which achievement is evaluated. When classrooms are organized around a single concept of competence, students are socialized to believe that ability is stable and restricted to a select group of individuals (Rosenholtz \& Simpson, 1984). Moreover, because performance is evaluated in a similar manner, it is easy for students to compare themselves with others and arrive at conclusions about who is and is not smart. These comparisons can have devastating effects on the motivation of students who do not perform well. For example, a classroom that emphasizes competence in literacy offers only a few standards against which all students will be judged. Students who are good readers and writers will feel efficacious. However, students who are poor readers but strong mathematicians are unlikely to develop positive beliefs about their abilities.

In contrast, a multidimensional classroom provides variety in learning tasks and evaluation strategies and gives all students a chance to demonstrate competence. By individualizing the goals you set for student performance, you can help students at different levels succeed (Maehr \& Midgley, 1991). Also, varying the nature and format of tasks gives more students an opportunity to display their strengths in at least some areas. As discussed above, permitting students some choice over what and how they learn can provide more avenues for success and yield substantial motivational benefits.
2. Use different grouping arrange ments. Students with low motivation may become even less interested in an activity when they are always placed in groups of low achievers $1 \mathrm{O}^{\prime}$ Connor, Atkinson, \& Horner, 1966). Group students differently for different subjects, and vary the composition of these groups. Classroom competition, often considered a motivational strategy, can create a climate in which students with disabilities most often lose. Losing decreases students' self-esteem and self-efficacy, and, therefore, is likely to lead to decreased motivation (Ames, 1984). Cooperative grouping structures, especially those in which everyone has the opportunity to contribute to the final outcome, can decrease competition and provide students with a meaningful way to demonstrate their talents.

3. Make sure your expectations for students' performance are clear, explicit, and understandable. Students' competence is fostered in situations in which there are clear expectations and frequent feedback about mastery (Skinner \& Belmont, 1993). However, students with disabilities may not understand classroom rules and procedures as readily as more successful students, particularly when expectations are implicit. Therefore, take special precautions to make sure students understand what is expected of them as well as the consequences for noncompliance. For example, plan lessons in which you teach procedures. Post rules around the classroom and give students their own copies, discussing rules and procedures with individuals as needed, and reviewing and reminding as often as required.

4. Avoid criticizing students publicly or displaying evidence of poor performance. Teachers should hold reasonable expectations for students' performance and be willing to express dissatisfaction when a student does not meet those expectations. Indeed, some research suggests that when teachers react to students' failures with sympathy, students come to believe they have low ability (Graham, 1990). Reactions of personal disappointment in or criticism of student performance are beneficial in some circumstances; they convey to a student that you believe he or she has the ability to do better. However, to maintain a student's selfesteem, criticism should be offered in private and should focus on specific components of poor performance rather than on performance in general. Make sure your appraisals are designed to convey information and are not merely emotional reactions to a student's performance. For example, discuss strategies that would help the student to improve, and convey your belief that he or she has the ability to do a better job next time.

5. Provide extra support to anxious students. Learning something new or confronting a difficult task can be frightening to students with a history of failure. Moreover, learning something well requires one to hypothesize, experiment, and explore without fear of making mistakes. Anxious students may need extra encouragement to take such risks. In some cases, this will require that you deemphasize or suspend evaluation of student performance, particularly when students are attempting something for the first time. When students know they will receive a grade, they are more likely to choose tasks they know they can do (Harter, 1978). Therefore, they are less likely to take the risks involved in trying something new. However, when students are encouraged to complete something for fun, they are more apt to choose a challenging task (Maehr \& Stallings, 1972).

Tests and evaluations induce anxiety in many students. You can help ease the anxiety inherent in these situations by giving students opportunities to review information (especially if it is unfamiliar), permitting them to correct their errors or retake examinations, allowing access to books and notes to reduce the emphasis on memorization, and sequencing activities so that students first encounter easy, and then more difficult, problems (Stipek, 1993). Stress that tests are opportunities to assess current understanding, rather than judgments of overall competence or abilities. Give instructions that encourage students to view abilities as amenable to change through hard work and appropriate strategies. Conclude tests or other evaluative activities with discussions of effective study habits and learning strategies that might help in the future.

\section{Self-Efficacy and Atributions}

Students' beliefs about their own abilities, or their self-efficacy, can have a strong influence on learning and per- 
formance. Self-efficacy influences students' willingness to begin difficult tasks, persistence at tasks in the face of failure, amount of effort expended, and the nature of thoughts and feelings during academic activities (Bandura, 1982; Schunk, 1985a). In addition to students' perceptions of their own competence as learners, their beliefs about the reasons for successes and failures at school tasks, or their attributions, play an important role in the development of achievement motivation (Borkowski, Carr, Rellinger, \& Pressley, 1990; Diener \& Dweck, 1978; Weiner, 1979, 1986). Educators should be aware of techniques and actions that can promote self-efficacy and adaptive attributions, and they should avoid practices that can have a deleterious effect on these factors.

1. Involve students in goal setting. Research has demonstrated that students with learning problems who set their own goals experience enhanced self-efficacy and better performance than students with teacher-assigned goals (Schunk, 1985a). As for the types of goals you should encourage or teach students to set, existing research shows that short-term goals that incorporate specific rather than general performance standards enhance students' self-efficacy and subsequent motivation (Schunk, 1985b). In addition, mastery goals, in which students are focused on improving their own performance and are less concerned with normative comparisons, are associated with higher levels of motivation (Ames \& Archer, 1988; Dweck, 1986).

2. Use attribution retraining techniques. Attribution retraining has been used successfully to help students develop more adaptive beliefs about the causes of their success and failure in school (Dweck, 1975). Teach students to attribute successes to their effort and developing abilities. When appropriate, give students feedback that they are trying hard and their skills are improving. Teach students to attribute failures to lack of effort (if this is indeed the case) and lack of effective learning strategies (Pearl, 1985). Researchers have found that students are more likely to maintain and generalize learning strategies if strategy instruction is combined with attribution retraining (Borkowski, Weyhing, \& Carr, 1988; Stevens \& Englert, 1993). So, teach students specific strategies that result in improved effort, and help them attribute their successes to the conscious use of these strategies (Licht \& Kistner, 1986). Be careful in your use of effort attributions, however. Telling students that success on easy tasks is due to high effort can lead them to believe that they have low ability (Graham, 1990).

3. Use cognitive mediation and selfcontrol training. Activities such as self-recording, graphing, goal setting, self-reinforcement, and self-instruction can be especially beneficial for enhancing students' self-efficacy (Zimmerman, 1990). These procedures provide students with tangible evidence of their progress and can help you draw attention to the relationships among effort, effective learning strategies, and positive outcomes. Moreover, they can help students maintain desirable behaviors and wean them from reliance on external sources of evaluation or reward. Be sure that students know how to perform the desired skill before expecting them to self-monitor or selfreinforce their use of it.

4. Be aware of the negative effects of extensive help giving and praise. Although used often by well-intentioned teachers, help giving and praise can have undesirable effects. When students receive too much help, they may not persist as long at difficult tasks (Farnham-Diggory \& Ramsey, 1971). Help should be given only when needed and then offered in a way that allows students to take some credit for their performance. Excessive praise, especially on easy tasks, can lead students to think that they have low ability (Graham, 1990; Stipek, 1993). Brophy (1981) has offered other helpful guidelines for the effective use of praise in educational settings.

\section{A Process Approach}

Many of the recommendations in the previous section can be implemented simultaneously. Motivational enrichment-the conscious planning, implementation, and evaluation of a variety of concurrent classroom practices that facilitate achievement motivation-may benefit many students in your class. By providing a range of motivational opportunities, teachers increase the probability that one or more of the specific practices will directly address specific students' needs. Be aware that when a collection of strategies is used with a group of students, certain strategies may increase achievement motivation for the majority but decrease motivation for an individual or subset of the group (Brophy, 1983). Therefore, you must anticipate that motivational practices will not be equally effective for every student and be prepared to implement motivational enrichment on an individual basis. The following steps can guide you in the selection of strategies to improve a specific student's achievement motivation.

1. Periodically screen all students for signs indicating that performance deficiencies may be motivational in nature. This practice can be implemented casually, by reviewing a class roster or grade book entries, and reflecting on whether specific students performing below expectations may be in need of motivational enrichment. Be alert to comments made by teachers, students, or parents that might indicate a student is unmotivated in a specific subject or area. Watch for changes in students' performance or products, such as a series of low scores on tests or carelessly completed homework, that might signal motivational difficulties.

2. Talk with the student suspected of having a motivational problem, and use the conversation to probe for further understanding of the student's problem. Cognitive-motivational theory places significant emphasis on the manner in which an individual judges and interprets his or her own behavior. Ask a student to "thinkaloud" about the reasons why he or she is doing poorly. Listen for statements that imply maladaptive beliefs or negative self-perceptions such as low ability and poor self-worth /"I'm just too dumb," or, "Nobody cares what I think"), lack of interest ("I just don't understand why I need to learn this stuff," or, "This stuff is sooo boring"), or anxiety about performance ("This work is too difficult," or, "I could never do that ${ }^{\prime \prime}$ ).

3. Explore informal use of questionnaires and scales that have been developed to assess motivational domains related to school performance. McCombs (1990) has described a variety of instruments that provide information about student motivation. The majority of the instruments listed are completed by students and can help a teacher examine motivational beliefs 
with respect to categories that include self-efficacy, attributions, perceptions of control, and preference for challeng. ing school tasks. These instruments must be used cautiously, however. They should never be applied as a sole measure to diagnose a student as having a "motivational problem." Rather, they should be one element of an array of information (e.g., observed behavior, anecdotal information, statements by the student, teacher's clinical judgments, etc.) that when analyzed as a whole, serves to verify that a motivational problem exists.

4. Before deciding on a strategy, evaluate prior techniques you have used to increase academic motivation and consider why they were successful or unsuccessful. The checklist in Figure 1 contains items pertaining to the recommendations discussed earlier. Using the checklist can help you reflect on approaches used in the past and reacquaint you with a range of alternatives that might more effectively facilitate achievement motivation for an individual or group of students.

5. Before beginning a new motivational strategy, confirm that the student is capable of performing the tasks or behaviors associated with the strategy. Always discuss the motivational strategies you decide to employ with the students for whom they were developed. Explain why you have chosen a particular strategy or modification and check to see if the student has the necessary skills or background knowledge. As discussed previously, simply making instructional choices available to a student does not mean that he or she has the skills and understanding to make those choices. For example, telling a student that he or she has the choice of submitting an assignment using a computer-generated printout or a handwritten paper may have little motivational effect if the student lacks the prerequisite skills for using a word processor. Similarly, informing a student that he or she has selected a very ambitious and long-term goal and strongly suggesting that he or she might want to reconsider doing only a part of the overall task assumes that the student has the skills to break the task down into more easily accomplished steps. Be prepared to provide students with appropriate instruction in the skills necessary to perform tasks believed to facilitate motivation.
6. Evaluate the effects of motivational enhancements. Specify what you will look for as evidence that a student's achievement motivation is improving. For example, you could assess whether the student participates more readily in class discussions, whether he or she makes more frequent positive comments about his or her skills, or whether he or she works independently for longer time periods. Then develop procedures for collecting systematic information about these behaviors. You might use anecdotal records, charts, graphs, or other recording procedures (Alberto \& Troutman, 1990). Don't overlook the possibility of involving students in collecting data about their behavior. As described above, selfmonitoring and self-recording are often powerful methods for improving student motivation. Look for incremental changes in behavior and continue to seek feedback from the student regarding ways in which his or her motivational beliefs may be shifting in a positive direction.

\section{Conclusion}

Enhancing students' achievement motivation is one of the most challenging tasks confronting educators of students with mild disabilities. These students often have experienced years of failure and defeat, of which diminished achievement motivation is a natural consequence. Therefore, changing students' motivation is likely to be a slow process. In addition, motivational goals may sometimes conflict with academic ones. For example, giving students choices over instructional activities may result in a seeming waste of precious instructional time if a student makes a poor choice and learns less than desired. Cooperative grouping practices may reduce time on task until students learn how to work together effectively. Or, attribution retraining activities may take time out of the curriculum that was reserved formerly for the presentation and practice of academic content.

However, motivated students will have developed the abilities and dispositions necessary to continue learning once they leave the classroom. Therefore, we believe that increased achievement motivation should be a primary goal in the education of students with mild disabilities, even if this goal sometimes conflicts with more tradi- tional goals of skill acquisition. Furthermore, consideration of achievement motivation should be a required element in every student's IEP. As discussed above, educators must consider the interaction between student characteristics and classroom practices in order to facilitate students' motivation. We hope the recommendations provided in this article give you some practical ideas for enhancing students' achievement motivation.

Cynthia M. Okolo, PhD, is an associate professor of educational studies at the University of Delaware. Christine M. Bahr, PhD, is an associate professor, Department of Special Education, Western Michigan University. J. Emmett Gardner, $\mathrm{PhD}$, is an assistant professor in the special education program at the University of Oklahoma. Address: Cynthia M. Okolo, Department of Educational Studies, University of Delaware, Newark, DE 19713.

\section{Authors' Note}

This article is based on a presentation given by the authors at the 1992 Council for Exceptional Children Convention in Baltimore, Maryland.

\section{References}

Alberto, P., \& Troutman, A. (1990). Applied behavior analysis for teachers. Columbus, $\mathrm{OH}$ : Merrill.

Ames, C. (1984). Competitive, cooperative, and individualistic goal structures: A motivational analysis. In R. Ames \& C. Ames (Eds.), Research on motivation in education: Student motivation (pp. 177-208). New York: Academic Press.

Ames, C., \& Archer, J. (1988). Achievement goals in the classroom: Student learning strategies and motivational processes. Journal of Educational Psychology, 80, 260-267.

Anand, P. G., \& Ross, S. M. (1987). Using computerassisted instruction to personalize arithmetic materials for elementary school children. Journal of Educational Psychology, 79, 72-78.

Atkinson, J. W. (1966). Motivational determinants of human behavior. In J. W. Atkinson \& N.T. Feather (Eds.), A theory of achievement motivation (pp. 11-48). New York: Wiley.

Bandura, A. (1982). Self-efficacy mechanism in human agency. American Psychologist, 37, 122-147.

Beaver, J. F. (1991). Making word problems relevant to your students. The Computing Teacher, 19(3), 50-51.

Borkowski, J. G., Carr, M., Rellinger, L., \& Pressley, M. (1990). Self-regulated cognition: Interdependence of metacognition, attributions, and self-esteem. In B. Jones \& L. Idol (Eds.), Dimensions of thinking and cognitive instruction (Vol. 1, pp. 53-92). Hillsdale, NJ: Erlbaum. 
Borkowski, J. G., Weyhing, R. S., \& Carr, M. (1988). Effects of attributional retraining on strategy-based reading comprehension in learning disabled students. Journal of Educational Psychology, 80, 46-53.

Brophy, J. (1981). Teacher praise: A functional analysis. Review of Educational Research, 51, 5-32.

Brophy, J. (1983). Conceptualizing student motiva tion. Educational Psychologist, 80, 200-215.

Brophy, J. (1987). Synthesis of research on strategies for motivating students to learn. Educational Leadership, 45(2), 40-48.

Carrier, C. A. (1984). Do learners make good choices? Instructional Innovator, 29(2), 15-17, 48.

Csikszentmihalyi, M., \& Nakamura, J. (1989). The dynamics of intrinsic motivation: A study of adolescents. In C. Ames \& R. Ames (Eds.), Research on motivation in education. Volume 3: Goals and cog nitions (pp. 45-71). San Diego: Academic Press.

deCharms, R. (1968). Personal causation. New York: Academic Press.

Deci, E. L. (1971). Effects of externally mediaied rewards on intrinsic motivation. Journal of Personality and Social Psychology, 18, 105-115.

Deci, E. L., \& Ryan, R. M. (1985). Intrinsic motivation and self-determination in human behavior. New York: Plenum.

Deci, E. L., Schwartz, A. J., Sheinman, L., \& Ryan, R. M. (1981). An instrument to assess adults' orientations toward control versus autonomy with children: Reflections on intrinsic motivation and perceived competence. Journal of Educational Psychology, $73,642-650$

Dembo, M. H. (1988). Applying educational psychology in the classroom (3rd ed.). White Plains, NY: Longman.

Dewey, J. (1913). Interest and effort in education. New York: Houghton Mifflin.

Diener, C., \& Dweck, C. (1978). An analysis of learned helplessness: Continuous changes in performance, strategy, and achievement cognitions following failure. Journal of Personality and Social Psychology, 36, 451-462.

Dweck, C. S. (1975). The role of expectations and attributions in the alleviation of learned helplessness. Journal of Personality and Social Psychology, $31,674-685$.

Dweck, C. S. (1986). Motivational processes affecting learning. American Psychologist, 41, 1040-1048.

Farnham-Diggory, S., \& Ramsey, B. (1971). Play persistence: Some effects of interruptions, social reinforcement, and defective toys. Developmental Psychology, 4, 297-298.

Findley, M. D., \& Cooper, H. (1983). Locus of control and academic achievement: $A$ review of the literature. Journal of Personality and Social Psychology, 44, 419-427.

Fuchs, L. S., \& Deno, S. L. (1991). Paradigmatic distinctions between instructionally relevant measurement models. Exceptional Children, 57, 488-500.
Gay, G. (1986). Interaction of learner control and prior understanding in computer-assisted video instruction. Educational Psychology, 78, 225-227.

Graham, S. (1990). Communicating low ability in the classroom: Bad things that good teachers sometimes do. In S. Graham \& V. S. Folkes (Eds.) Attribution theory: Applications to achievement, mental health, and interpersonal conflict (pp. 17-36). Hillsdale, NJ: Erlbaum.

Greene, D., \& Lepper, M. R. (1974). Effects of extrinsic rewards on children's subsequent performance. Child Development, 45, 1141-1145.

Hannafin, M. J. (1984). Guidelines for using locus of instructional control in the design of computerassisted instruction. Journal of Instructional Development, 7(3), 6-10.

Harter, S. (1978). Pleasure derived from challenge and the effects of receiving grades on children's difficulty level choices. Child Development, 49, 788-799

Kazdin, A. E., \& Bootzin, R. R. (1972). The token economy: An evaluative review. Journal of Applied Behavior Analysis, 5, 343-372.

Keller, J. M. (1983). Motivational design of instruction. In C. M. Riegeltuh (Ed.), Instructional-design theories and models: An overview of their current status (pp. 383-434). Hillsdale, NJ: Erlbaum.

Kinzie, M. B., \& Sullivan, H. J. (1989). Continuing motivation, learner control, and CAI. Educational Technology Research and Development, 37(2), 5-14.

Klein, J. D., \& Keller, J. M. (1990). Influence of student ability, locus of control, and type of instructional control on performance and confidence. Journal of Educational Research, 83, 140-146.

Kruglanski, A. W., Friedman, I., \& Zeevi, G. (1971). The effects of extrinsic incentive on some qualitative aspects of task performance. Journal of Personality, 39, 606-617

Lepper, M. R. (1983). Extrinsic reward and intrinsic motivation: Implications for the classroom. In J. M. Levine \& M. C. Wang (Eds.), Teacher and student perceptions: Implications for learning (pp. 281-317). Hillsdale, NJ: Erlbaum.

Lepper, M. R. (1988). Motivational considerations in the study of instruction. Cognition and Instruction, 5, 289-309.

Lepper, M. R., \& Greene, D. (1975). Turning play into work: Effects of adult surveillance and extrinsic reward on children's intrinsic motivation. Journal of Personality and Social Psychology, 31, 479-486.

Lepper, M. R., \& Malone, T. W. (1987). Intrinsic motivation and instructional effectiveness in computer-based education. In R. E. Snow \& M. J. Farr (Eds.), Aptitude, learning, and instruction: III. Cognitive and affective process analyses (pp. 255-296). Hillsdale, NJ: Erlbaum.

Licht, B. C., \& Kistner, J. A. (1986). Motivational problems of learning-disabled children: Individual differences and their implications for treatment. In J. K. Torgesen \& B. Y. L. Wong (Eds.), Psychological and educational perspectives on learning disabilities (pp. 225-255). New York: Academic Press.
López, C. L., \& Sullivan, H. J. (1992). Effect of personalization of instructional context on the achievement and attitudes of Hispanic students. Educational Technology Research and Development, 40(4), 5-13.

Maehr, M. L., \& Midgley, C. (1991). Enhancing stu dent motivation: A schoolwide approach. Educational Psychologist, 26, 399-427.

Maehr, M., \& Stallings, W. (1972). Freedom from external evaluation. Child Development, 43, $117-185$.

Malone, T. W., \& Lepper, M. R. (1987). Making learning fun: A taxonomy of intrinsic motivation for learning. In R. E. Snow \& M. C. Farr (Eds.), Aptitude, learning, and instruction: III. Cognitive and affective process analyses (pp. 223-253). Hillsdale, NJ: Erlbaum.

Malouf, D. B. (1983). What rewards reduce student motivation? School Psychology Review, 12, $1-11$.

McCombs, B. L. (1990). The definition and measurement of primary motivational processes. In M. C. Wittrock \& E. L. Baker (Eds.), Testing and cognition (pp. 63-81). Englewood Cliffs, NJ: Prentice-Hall.

Morgan, M. (1984). Reward-induced decrements and increments in intrinsic motivation. Review of Educational Research, 54, 5-30.

O'Connor, P., Atkinson, J. W., \& Horner, M. (1966). Motivational implications of ability grouping in schools. In J. W. Atkinson \& N. T. Feather (Eds.), A theory of achievement motivation (pp. 231-259). New York: Wiley.

Okolo, C., Hinsey, M., \& Yousefian, B. (1990). Learning disabled students' acquisition of keyboarding skills and continuing motivation under drill-and-practice and game conditions. Learning Disabilities Research, 5, 100-109.

O'Leary, K. D., \& Drabman, R. (1971). Token reinforcement programs in the classroom: A review. Psychological Bulletin, 75, 379-398.

Pearl, R. (1985). Cognitive-behavioral interventions for increasing motivation. Journal of Abnormal Child Psychology, 13, 443-454.

Pintrich, P. R., Marx, R. W., \& Boyle, R. A. (1993). Beyond cold conceptual change: The role of motivational beliefs and classroom contextual factors in the process of conceptual change. Review of Educational Research, 63, 167-199.

Resnick, L. B., \& Klopfer, L. E. (1989). Toward the thinking curriculum: An overview. In L. Resnick \& L. E. Klopfer (Eds.), Toward the thinking curriculum: Current cognitive research (pp. 1-18). Pittsburgh, PA: Association for Supervision and Curriculum Development.

Rigby, C. S., Deci, E. L., Patrick, B. C., \& Ryan, R. M. (1992). Beyond the intrinsic-extrinsic dichotomy: Self-determination in motivation and learning. Motivation and Emotion, 16, 165-185.

Rosenholtz, S., \& Simpson, C. (1984). The formation of ability conceptions: Developmental trend or social construction? Review of Educational Research, 54, 31-63.

(continued on p. 312) 